\title{
Incidence and risk factors of preoperative deep venous thrombosis following pelvic and acetabular fractures: a retrospective case- control study
}

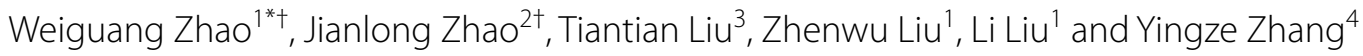

\begin{abstract}
The objective of this study was to investigate the prevalence of preoperative deep venous thrombosis (DVT) in the pelvic cavity and lower extremities following pelvic and acetabular fractures and to identify the risk factors of the occurrence of DVT. Duplex ultrasound (DUS) screening and blood tests were conducted in patients admitted from June 2012 to December 2020 for surgical treatment of pelvic and acetabular fractures. Univariate analyses were performed on data of demographics, comorbidities, time from injury to surgery, injury mechanism, accompanied injury, and laboratory results. The optimal cutoff values of continuous variables with statistical significance were obtained by using the receiver operating characteristic (ROC) curve. A multivariate logistic regression analysis was then employed to examine the independent values in terms of predicting preoperative DVT. A total of 607 patients with pelvic and acetabular fractures were included, among whom 82 (13.5\%) patients sustained preoperative DVTs. Specifically, 31.7\% (26/82) were diagnosed with proximal DVTs. Fifty-two (63.4\%) patients had DVT within 7 days after injury, and 67 (81.7\%) patients within 10 days. The multivariate logistic regression analysis identified 6 factors independently associated with the presence of preoperative DVT, including age $>46$ years (odds ratio $[O R]=2.94$ ), $\mathrm{BMl}>26.73 \mathrm{~kg} / \mathrm{m}^{2}$ $(\mathrm{OR}=3.91)$, time from injury to surgery $>9$ days $(\mathrm{OR}=5.39)$, associated injury $(\mathrm{OR}=7.85), \mathrm{ALB}<32.8 \mathrm{~g} / \mathrm{L}(\mathrm{OR}=2.71)$ and FIB $>3.095 \mathrm{~g} / \mathrm{L}(\mathrm{OR}=3.34)$. Despite the modern prophylactic regimen, the preoperative DVT in patients with pelvic and acetabular fractures still draws the attention of orthopaedic surgeons. Better understanding these risk factors can help surgeons refine the risk stratification profile and perform early interdisciplinary management for patients at high risk of DVT.
\end{abstract}

\section{Background}

Pelvic and acetabular fractures are commonly caused by blunt high-energy potentially life-threatening injuries, and their perioperative management remains controversial and challenging $[1,2]$. Trauma-related endothelial damage, venous stasis, and systematical hypercoagulation

\footnotetext{
*Correspondence: zhaoweiguang361@163.com

'Weiguang Zhao and Jianlong Zhao contributed equally to this work

1 Department of Orthopaedic Surgery, Handan Central Hospital, Handan 056000, Hebei, People's Republic of China

Full list of author information is available at the end of the article
}

pose patients at substantial risk of venous thromboembolic events. DVT sometimes accompanied by pulmonary embolism contributes to the most principal cause of surgical morbidity and mortality in this subpopulation. Without prophylactic treatment, the rate of DVT following pelvic trauma is documented to be high ranging from 35 to $61 \%$ with a large proportion of proximal emboli observed [3,4]. Although extensive regimes for DVT prophylaxis have been explored in orthopaedic patients [5], the rate of the thromboembolic event still varies, from 5 to $34 \%$ in this high-risk group [6, 7], which

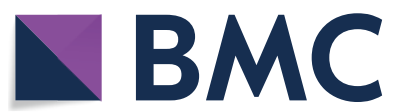

(c) The Author(s) 2022. Open Access This article is licensed under a Creative Commons Attribution 4.0 International License, which permits use, sharing, adaptation, distribution and reproduction in any medium or format, as long as you give appropriate credit to the original author(s) and the source, provide a link to the Creative Commons licence, and indicate if changes were made. The images or other third party material in this article are included in the article's Creative Commons licence, unless indicated otherwise in a credit line to the material. If material is not included in the article's Creative Commons licence and your intended use is not permitted by statutory regulation or exceeds the permitted use, you will need to obtain permission directly from the copyright holder. To view a copy of this licence, visit http://creativecommons.org/licenses/by/4.0/. The Creative Commons Public Domain Dedication waiver (http://creativecommons.org/publicdomain/zero/1.0/) applies to the data made available in this article, unless otherwise stated in a credit line to the data. 
places these patients at increased risk for fatal pulmonary embolism intraoperatively and postoperatively and necessitate aggressive therapy. Therefore, it appears to be particularly significant to highlight early screening of DVT after pelvic trauma.

Consensus on the routine chemoprophylaxis for elective orthopaedic surgeries (hip or knee arthroplasty) has been reached and explicitly validated. However, the importance of thromboprophylaxis following pelvic and acetabular fractures is undervalued due to a lack of refined data of DVT, manifesting large variations in incidence, risk factors, screening methodologies, anatomic locations of clots, and optimal thrombosis [6-9]. DVTs were considered a rare entity in the previous literature, while an increasing body of evidence indicates that Asian patients have a similar prevalence of DVT to that in Caucasians $[7,10,11]$. During the recent decades, Asian countries are bearing a growing incidence of high-velocity traumas, including pelvic and acetabular fractures, which can be treated surgically with satisfactory results $[12,13]$. However, there is still no definite information on the characteristics of DVT focusing on the period from pelvic and acetabular fractures to surgical procedures.

Taken together, the data regarding incidence and risk factors specific to the subgroup with pelvic and acetabular fractures are scarce. The objectives of this study included: (1) to investigate the incidence of DVT during the preoperative hospital stay for surgically treated pelvic and acetabular fractures, and (2) to identify the risk factors independently associated with the occurrence of DVT by employing statistical analyses.

\section{Materials and methods}

This retrospective, single-center study was performed following principles of the international guidelines for human research protections, the Declaration of Helsinki, and it was in line with Strengthening the Reporting of Observational Studies in Epidemiology (STROBE) Guidelines. All components of the study were approved by and covered under the Institutional Review Board, Faculty of Medicine, Handan Central Hospital, Handan, China. Informed consent was signed by all the participants. All the patients included in this research were admitted to our hospital from June 2012 to December 2020 for surgical treatment of pelvic and acetabular fractures. The study period started from injury to either occurrence of DVT or operation. All the data were abstracted from the radiology information system and electronic medical record system.

\section{Inclusion and exclusion criteria}

Inclusion criteria were (1) patients admitted to our institution from June 2012 to December 2020 and received surgical treatment, (2) age of 18 years and older, and (3) definite diagnosis of pelvic and/or acetabular fractures with complete medical data. Exclusion criteria were (1) pathological (metastatic) fracture, (2) injury associated with the fracture that required immediate surgical intervention, (3) active malignant tumor, (4) a history of venous thromboembolic disease, or (5) recent use of anticoagulants for other indications within 3 months.

\section{Data acquisition and variables of interest}

The inpatients' comorbidities and demographic data were retrieved from the electronic medical record system, radiographic image, and operation report system. The information included sex, age, body mass index (BMI), diabetes mellitus, chronic heart disease, hypertension, smoking habits (current smoker or not), alcohol consumption (daily drinker or not). Trauma-related data comprised the following information: (1) type of fracture: pelvic ring fractures being classified according to Young-Burgess classification [14] and acetabular fractures according to Judet-Letournel classification [15]; (2) injury mechanism: lower-energy fracture was defined as a fracture caused by fall from standing height or low height of less than $1 \mathrm{~m}$, and high-energy fracture as from high height, motor vehicle accidents [16]; (3) concomitant injuries (involving the chest, long bone fracture, spine, head, and abdomen); (4) time from injury to the operation of osteosynthesis; and (5) American Society of Anesthesiologists (ASA) classification. Fracture patterns were independently reviewed based on X-rays and computed tomography scans by two senior orthopaedic surgeons to obtain a consistent interpretation of the images. Combined pelvic and acetabular fractures are classified as one certain fracture type according to which was dominant (pelvic or acetabular fracture).

Overnight fasting blood samples were drawn and measured at the central laboratory of our institution according to the manufacturers' instructions. The reference value of each inspection item was determined by the laboratory before reporting the patient's test results. Hematological indicators of interest included albumin (ALB) level, high-density lipoprotein cholesterol (HDL-C) level, lowdensity lipoprotein cholesterol (LDL-C) level, very-lowdensity lipoprotein (VLDL) level, red blood cell (RBC) count, hemoglobin (HGB) level, platelet (PLT), prothrombin time $(\mathrm{PT})$, activated partial thromboplastin time (APTT), fibrinogen (FIB) and D-dimer level.

\section{Diagnosis and prophylaxis of DVT}

Venography was taken as the golden standard if DVT could not be ruled out by the duplex ultrasound (DUS) screening. All the patients underwent DUS screening and monitoring on bilateral lower extremities and pelvis 
with Philips Affiniti50 ultrasonographic machine (Royal Phillips Electronics, Amsterdam, The Netherlands) after admission, every 5-7 days or when any suspected symptoms appeared, according to authors' institutional protocol. Senior sonographers performed the scanning from the calf veins to iliac veins for positive DVTs. The diagnostic criteria included direct visualization of intraluminal thrombus, the presence of an intraluminal defect, loss of compressibility of the vein, blunted or inadequate flow augmentation, and lack of spontaneous and respirophasic flow above the knee segments [17]. Spiral computed tomography angiography was taken when any symptoms and signs indicative of suspected pulmonary embolism presented or definitive diagnosis of DVT in pelvic veins could not be obtained based on DUS. Proximal DVT was defined if it was localized in popliteal and proximally, and thrombosis that occurred from the distal to popliteal vein was classified as distal DVT. According to ultrasonographic and radiological results, the patients were divided into 2 groups, a DVT group and a non-DVT group.

After admitted to the hospital with a negative result of DVT, all the patients were administered with intermittent pneumatic compression on lower limbs and a prophylactic dose of the low-molecular-weight heparin (enoxaparin, $20-40 \mathrm{mg}$ or dalteparin, $2500-5000 \mathrm{IU}$, once daily) within 48 h. For those with hemodynamic instability, pharmacological prophylaxis was prescribed once stable. Patients with positive DVTs were given therapeutic anticoagulants (enoxaparin, $20-40 \mathrm{mg}$ or dalteparin, 2500-5000 IU, twice daily), and withheld the mechanical prophylaxis immediately. For patients with proximal DVT, preoperative placement of a retrievable vena cava filter was performed as prophylaxis against intraoperative and postoperative pulmonary embolism. Chemical prophylaxis was stopped $12 \mathrm{~h}$ before surgery.

\section{Statistical analysis}

All the statistical analyses were employed by SPSS26.0 (IBM, Armonk, New York, USA). Continuous variables were expressed as mean \pm standard deviation (SD)/ median (upper quartile, lower quartile). The Kolmogorov-Smirnov test was performed to evaluate the normality of the continuous data, and then, these data were compared between DVT group non-DVT group by using Student- $t$ test or Mann-Whitney $U$ test, as appropriate. Variables with statistical significance $(p<0.05)$ were analyzed by using the receiver operating characteristic (ROC) curve to obtain the optimal cutoff values associated with the presence of DVT. Afterward, these factors were converted from continuous variables into categorical variables. A Pearson Chi-square test or Fisher's exact test was used, to evaluate the association between inter-groups, expressed as number and percentage. A multivariate logistic regression analysis was performed to examine the independent value of each significant variable from the univariable analyses in terms of predicting the outcome of preoperative DVT. Variables with a p-value less than 0.10 were retained in the final model, and the correlation strength was represented by odds ratio (OR) and $95 \%$ confidence interval $(95 \% \mathrm{CI})$. The fitting degree of the model was evaluated by HosmerLemeshow $(\mathrm{H}-\mathrm{L})$ test. Data with a $p$-value less than 0.05 were considered statistically significant.

\section{Results}

\section{The baseline of the patients}

In total, 607 patients with pelvic and acetabular fractures were included in this study. There were 342 males and 265 females with a mean age of $45.4 \pm 14.3$ years (range:18-90). According to the results of fracture classification, 291 had pelvic fractures (simple type in 159 patients, complex type in 132 patients), and 316 patients sustained acetabular fractures (anterior-posterior compression type in 98 patients, lateral compression type in 189 patients, vertical shear-type in 20 patients, and combined mechanism type in 9) (See Table 1).

\section{Characteristics of preoperative DVT}

The mean time from injury to the diagnosis of DVT was 6.4 days, ranging from 1 to 16 . Of the total 607 patients, 82 patients had DVT before surgery. The overall incidence is $13.5 \%(82 / 607)$ and specifically, $31.7 \%(26 / 82)$ was diagnosed with proximal DVTs, which required placement of a vena cava filter. To be noted, in those with proximal DVTs, only 5 patients had an isolated thrombus in the thigh or pelvic vein, each of the other 21 patients had multiple thrombi in both proximal and distal veins at the first detection time of DVT. There were 13 cases of DVT in bilateral lower limbs and 69 cases in unilateral extremities. Twenty-four cases of DVT occurred in

Table 1 The incidence of DVT in pelvic and acetabular fractures

\begin{tabular}{lcc}
\hline Classification & No. (\%) of patients & No. (\%) of DVT \\
\hline Pelvic fractures & $291(47.9 \%)$ & $36(43.9 \%)$ \\
Simple & $159(26.2 \%)$ & $16(19.5 \%)$ \\
Complex & $132(21.7 \%)$ & $20(24.4 \%)$ \\
Acetabular fractures & $316(52.1 \%)$ & $47(57.3 \%)$ \\
APC & $98(16.1 \%)$ & $11(13.4 \%)$ \\
LC & $189(31.1 \%)$ & $19(23.2 \%)$ \\
VS & $20(3.3 \%)$ & $12(14.6 \%)$ \\
CM & $9(1.5 \%)$ & $5(6.1 \%)$ \\
Total & $607(100 \%)$ & $82(100 \%)$ \\
\hline
\end{tabular}

$\mathrm{APC}$, anterior-posterior compression; LC, lateral compression; VS, vertical shear; $\mathrm{CM}$, combined mechanism 
the injured limbs, 3 in uninjured limbs, and 1 in bilateral limbs. The mean time from injury to the diagnosis of DVT was 6.4 days, ranging from 1 to 16. Fifty-two (63.4\%) patients had DVT within 7 days after injury, and $67(81.7 \%)$ patients within 10 days. During the research period, no pulmonary embolism or uncontrolled bleeding was observed in patients.

\section{Optimal cut-off and univariate analysis}

The comparison of continuous variables in patients with or without DVT was conducted, and the results are listed in Table 2.

As shown in the table, we found significant differences between the two groups concerning age, BMI, the time from injury to surgery, and blood parameters including ALB, PLT, and FIB. Not surprisingly, the ROC analysis showed significant results regarding the abovementioned factors (see Fig. 1). The optimal cutoff values of the age, BMI, time from injury to surgery, ALB, PLT, and FIB were 46 years, and $26.73 \mathrm{~kg} / \mathrm{m}^{2}, 9$ days, $32.8 \mathrm{~g} / \mathrm{L}$, $332.5 * 10^{9} / \mathrm{L}$, and $3.09 \mathrm{~g} / \mathrm{L}$, respectively (Table 3 ). The cutoff value was then used to classify the continuous variable into two categories. The univariate analysis results

Table 2 Comparison of continuous variables in patients with or without preoperative DVT following pelvic and acetabular fracture

\begin{tabular}{lccc}
\hline Variable & $\begin{array}{l}\text { DVT group } \\
(\boldsymbol{n}=\mathbf{8 2}) \\
(\boldsymbol{m e a n} \pm \mathbf{S D})\end{array}$ & $\begin{array}{l}\text { Non-DVT } \\
\text { group }(\boldsymbol{n}=\mathbf{5 2 5}) \\
(\boldsymbol{m e a n} \pm \mathbf{S D})\end{array}$ & $\boldsymbol{p}$ value \\
\hline Age (years) & $51.59 \pm 14.8$ & $44.41 \pm 13.9$ & $<0.001^{\text {*a }}$ \\
BMl, kg/m² & $26.5 \pm 3.2$ & $25.00 \pm 3.5$ & $0.005^{* a}$ \\
Time from & $12.41 \pm 4.1$ & $7.78 \pm 4.3$ & $<0.001^{* \mathrm{~b}}$ \\
injury to & & & \\
surgery & $32.75 \pm 4.8$ & $34.29 \pm 5.5$ & $0.017^{* a}$ \\
ALB & $0.96 \pm 0.3$ & $1.00 \pm 0.3$ & $0.311^{\mathrm{b}}$ \\
HDL-C & $2.39 \pm 0.7$ & $2.32 \pm 0.8$ & $0.438^{\mathrm{b}}$ \\
LDL-C & $0.61 \pm 0.3$ & $0.57 \pm 0.3$ & $0.292^{\mathrm{b}}$ \\
VLDL & $3.58 \pm 0.5$ & $3.58 \pm 0.56$ & $0.993^{\mathrm{a}}$ \\
RBC & $110.24 \pm 13.8$ & $111.28 \pm 17.6$ & $0.813^{\mathrm{b}}$ \\
HGB & $305.35 \pm 118.1$ & $255.81 \pm 107.6$ & $<0.001^{* \mathrm{~b}}$ \\
PLT & $12.31 \pm 1.5$ & $12.37 \pm 1.4$ & $0.755^{\mathrm{b}}$ \\
PT & $29.67 \pm 3.8$ & $29.34 \pm 3.7$ & $0.468^{\mathrm{b}}$ \\
APTT & $4.32 \pm 1.4$ & $3.74 \pm 1.4$ & $0.001^{* a}$ \\
FIB & $3.74 \pm 7.4$ & $3.19 \pm 2.7$ & $0.230^{\mathrm{b}}$ \\
D-dimer & &
\end{tabular}

DVT, deep vein thrombosis; BMI, body mass index; ALB, albumin; HDL-C, high-density lipoprotein cholesterol level; LDL-C, low-density lipoprotein cholesterol level; VLDL, very-low-density lipoprotein level; RBC, red blood cell; HGB, hemoglobin; PLT, platelet; PT, prothrombin time; APTT, activated partial thromboplastin time; FlB, fibrinogen

*Statistical significance

${ }^{\text {a }}$ Student- $t$ test

${ }^{\mathrm{b}}$ Mann-Whitney $U$ test revealed a statistically significant association between preoperative DVT and factors including age ( $>46$ years), BMI $\left(>26.73 \mathrm{~kg} / \mathrm{m}^{2}\right)$, hypertension, time from injury to surgery ( $>9$ days), associated injury, ASA classification (III-IV), ALB $(<32.8 \mathrm{~g} / \mathrm{L})$, PLT $(>332.5)$ and FIB $(>3.095 \mathrm{~g} / \mathrm{L})$ (see Table 4). Next, the 9 factors were subjected to the multivariate logistic regression analysis.

\section{Multivariate logistic regression analysis}

The multivariate logistic regression analysis showed 6 factors were identified independently associated with the presence of preoperative DVT. The adjusted results are summarized in Table 5, which were: age $>46$ years $(\mathrm{OR}=2.94), \quad \mathrm{BMI}>26.73 \mathrm{~kg} / \mathrm{m}^{2} \quad(\mathrm{OR}=3.91), \quad$ time from injury to surgery $>9$ days $(\mathrm{OR}=5.39)$, associated injury $(\mathrm{OR}=7.85), \mathrm{ALB}<32.8 \mathrm{~g} / \mathrm{L}(\mathrm{OR}=2.71)$ and $\mathrm{FIB}>3.095 \mathrm{~g} / \mathrm{L} \quad(\mathrm{OR}=3.34)$. The Hosmer-Lemeshow test demonstrated excellent fitness of the final model $\left(X^{2}=2.472, p=0.963\right.$; Nagelkerke $\left.R^{2}=0.457\right)$.

\section{Discussion}

To the best of our knowledge, this is one of the largest retrospective studies conducted on the incidence and risk factors of preoperative DVT in patients undergoing pelvic and acetabular fractures. Despite the use of the modern prophylactic regimen, our results indicated a $13.5 \%$ incidence of DVT before surgery, with $31.7 \%$ of those being proximal veins in origin. In addition to some well-established predisposing factors such as older age or obesity, other risk factors also exhibited independent association with preoperative DVT, which was partially consistent with prior studies on population with fractures [18-20]. However, the consensus on DVT management following pelvic and acetabular fractures has not been reached, largely due to their variations in diagnostic method and prophylactic protocol. For example, a prospective study by Kim et al. [7] showed that $33.7 \%$ of patients developed DVT screened by indirect CT venography, the higher incidence of which might be due to the absence of chemoprophylaxis. Another study revealed that with the routine use of pharmacological prophylaxis after pelvic trauma, the prevalence of thromboembolic events was $29.1 \%$ with more than $60 \%$ of those DVTs being proximal [8], while this study did not differentiate the pre-and post-operative DVTs, thus giving rise to the discrepancy between their conclusions and the results of the current study. The previous literature demonstrated that manipulation during surgery predisposed patients with pelvic trauma at higher risk of vascular injury [3]. Hence, we considered the surgery itself another possible risk factor for DVT to focus on the early identification and prevention of DVT following trauma. Overall, our findings showed that patients with pelvic and acetabular 


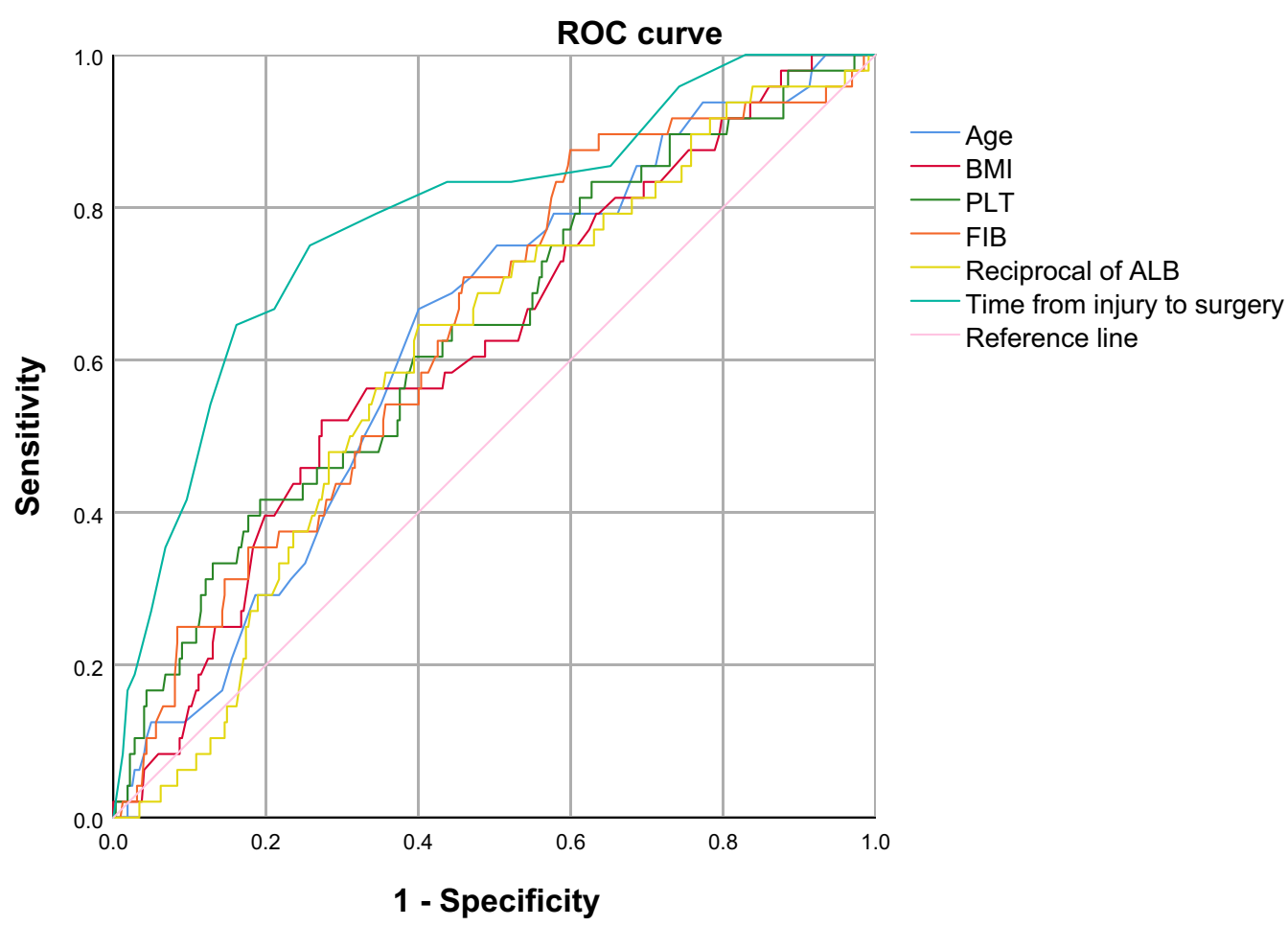

Fig. 1 The ROC curve of 6 continuous variables with statistical significance cutoff values. The optimal predictive values of age, BMI, PLT, FIB, ALB and the time from injury to surgery were $46,26.73,332.5,3.09,32.8$ and 9 , respectively

Table 3 The ROC curve analysis of continuous variables with statistical significance

\begin{tabular}{|c|c|c|c|c|c|}
\hline Variable & Cutoff value & Sensitivity (\%) & Specificity (\%) & AUC $(95 \% \mathrm{Cl})$ & $P$ value \\
\hline Age, years & 46 & 66.7 & 59.9 & $0.629(0.551-0.707)$ & 0.004 \\
\hline $\mathrm{BMI}\left(\mathrm{Kg} / \mathrm{m}^{2}\right)$ & 26.73 & 52.1 & 72.7 & $0.619(0.536-0.702)$ & 0.008 \\
\hline $\operatorname{PLT}\left(* 10^{9} / \mathrm{L}\right)$ & 332.5 & 41.7 & 80.7 & $0.636(0.551-0.721)$ & 0.002 \\
\hline $\mathrm{FIB}(\mathrm{g} / \mathrm{L})$ & 3.09 & 87.5 & 40.1 & $0.640(0.560-0.721)$ & 0.002 \\
\hline ALB (g/L) & 32.8 & 64.6 & 59.9 & $0.607(0.527-0.687)$ & 0.017 \\
\hline $\begin{array}{l}\text { Time from injury to sur- } \\
\text { gery, days }\end{array}$ & 9 & 75.0 & 74.2 & $0.786(0.713-0.858)$ & $<0.001$ \\
\hline
\end{tabular}

fractures had a significantly increased risk of developing DVT and the chemical prevention strategy should be advocated in DVT management during the preoperative hospital stay.

Increased age has been well-acknowledged as one of the principal risk factors for thromboembolic diseases, particularly in trauma patients $[7,20,21]$, although no strong association between old age and DVT was found in some literature [9]. In this study, the univariable analysis results showed the mean age of patients with preoperative DVT was 7.18 years older than those without DVT (51.59 years vs 44.41 years) $(p<0.001)$, and the morbidity of DVT in patients aged older than 46 years was
$67.1 \%$, significantly higher than the rate of their counterparts $(43.2 \%, p<0.001)$. After adjusting the confounding factors, we found the patients with pelvic and acetabular fractures over 46 years old had a 2.94-fold increased risk of DVT than that of the younger ones. Similarly, Kim et al. [7] and Wang et al. [8] identified that elderly patients had a greater risk of DVT following pelvic and acetabular fractures. The interrelation between them has not been understood by far, while was considered to relate with increasing presence of other comorbidity or enhanced coagulation potential with aging [22]. Given that the DVT screening strategy and prophylaxis regimen were not age-adjusted in this current study, and the effect 
Table 4 Univariate analyses of categorical variables with interest

\begin{tabular}{|c|c|c|c|}
\hline Variables & Number (\%) of DVT $(n=82)$ & Number (\%) of non-DVT $(n=525)$ & $P$ value \\
\hline Gender (male) & $54(65.9)$ & $288(73.9)$ & 0.128 \\
\hline Age ( $>46$ years) & $55(67.1)$ & $227(43.2)$ & $<0.001^{*}$ \\
\hline $\mathrm{BMI}\left(>26.73 \mathrm{~kg} / \mathrm{m}^{2}\right)$ & $42(51.2)$ & $142(27.0)$ & $0.001^{*}$ \\
\hline Diabetes mellitus & $9(11.0)$ & $89(17.0)$ & 0.171 \\
\hline Hypertension & $20(24.4)$ & $59(11.2)$ & $0.001^{*}$ \\
\hline Chronic heart disease & $8(9.8)$ & $25(4.8)$ & 0.064 \\
\hline Current smoking & $8(9.8)$ & $47(9.0)$ & 0.814 \\
\hline Alcohol consumption & $8(9.8)$ & $47(9.0)$ & 0.814 \\
\hline Time from injury to surgery (>9 days) & $61(74.4)$ & $151(28.8)$ & $<0.001^{*}$ \\
\hline Injury mechanism (high-energy) & $72(87.8)$ & $478(91.0)$ & 0.349 \\
\hline Accompanied injury & $68(82.9)$ & $132(25.1)$ & $<0.001^{*}$ \\
\hline ASA classification (III-IV) & $47(57.3)$ & $141(26.9)$ & $<0.001^{*}$ \\
\hline $\operatorname{ALB}(<32.8 \mathrm{~g} / \mathrm{L})$ & $47(57.3)$ & $211(40.2)$ & $0.004^{*}$ \\
\hline $\mathrm{HDL}-\mathrm{C}(<1.1 \mathrm{mmol} / \mathrm{L})$ & $57(69.5)$ & $339(64.6)$ & 0.382 \\
\hline LDL-C (>3.37 mmol/L) & $4(4.9)$ & $49(9.3)$ & 0.184 \\
\hline VLDL (>0.78 mmol/L) & $14(17.1)$ & $85(16.2)$ & 0.841 \\
\hline RBC (<lower limit) & $71(86.6)$ & $441(84.0)$ & 0.549 \\
\hline HGB (<lower limit) & $86(82.9)$ & $425(81.0)$ & 0.670 \\
\hline PLT (> 332.5) & $30(36.6)$ & $99(18.9)$ & $<0.001^{*}$ \\
\hline $\mathrm{PT}<10 \mathrm{~s}$ & $1(1.2)$ & $6(1.1)$ & 0.952 \\
\hline APTT $<28 \mathrm{~s}$ & $23(28.0)$ & $183(34.9)$ & 0.226 \\
\hline FIB (>3.095 g/L) & $68(82.9)$ & $302(57.5)$ & $<0.001^{*}$ \\
\hline D-Dimer (> 0.5 mg/L) & $71(86.6)$ & $410(78.1)$ & 0.078 \\
\hline
\end{tabular}

ASA, the American Society of Anesthesiologists; RBC, red blood cell, reference range: female, 3.5-5.0*10 $12 / \mathrm{L}$; males, 4.0-5.5*10 $0^{12} / \mathrm{L}$. HGB hemoglobin, reference range: females, $110-150 \mathrm{~g} / \mathrm{L}$; males, $120-160 \mathrm{~g} / \mathrm{L}$

*Statistical significance

Table 5 Multivariate analysis of risk factors associated with preoperative DVT

\begin{tabular}{lllll}
\hline Variables & OR & \multicolumn{2}{l}{$\mathbf{9 5 \% \mathrm { Cl }}$} & P value \\
\cline { 3 - 4 } & & Lower limit & Upper limit & \\
\hline $\mathrm{BMI}>26.73 \mathrm{~kg} / \mathrm{m}^{2}$ & 3.91 & 1.787 & 8.540 & 0.001 \\
$\mathrm{Age}>46$ years & 2.94 & 1.387 & 6.244 & 0.005 \\
$\mathrm{ALB}<32.8 \mathrm{~g} / \mathrm{L}$ & 2.71 & 1.261 & 5.830 & 0.011 \\
$\mathrm{FIB}>3.09 \mathrm{~g} / \mathrm{L}$ & 3.34 & 1.329 & 8.406 & 0.010 \\
Associated injury & 7.85 & 3.611 & 17.056 & $<0.001$ \\
$\begin{array}{l}\text { Time from injury to } \\
\text { surgery }>9 \text { days }\end{array}$ & 5.39 & 2.475 & 11.735 & $<0.001$ \\
\hline
\end{tabular}

of old age on thrombosis was likely to be underestimated in some certain frail elderly patients. Therefore, DVTrelated screening and prophylaxis should be highlighted for elderly patients with pelvic ring and acetabular injury.

It has been widely recognized that orthopaedic patients with elevated BMI have a higher risk of perioperative complications than patients within the normal range $[23,24]$. However, the impact of elevated BMI on the presence of DVT was not shown in some investigations, partially due to the small sample size as well as to numerous heterogeneities in research objects and study design and screening method $[7,8,19]$. Obesity in the current study was defined as a BMI value over $26.73 \mathrm{~kg} / \mathrm{m}^{2}$, which was determined according to the ROC analysis. It was found that obesity resulted in 3.91-time increased odds of developing DVT in this trauma group $(p=0.001)$. Similar findings have been reported by Morris et al. [25] who found a significantly increased obesity-related risk of complications including DVT after pelvic and acetabular trauma. In addition, Karunakar et al. [26] reported that patients with $\mathrm{BMI} \geq 30$ were 2.1 -fold more likely to develop DVT than those with $\mathrm{BMI}<25$ after acetabular fractures. The underlying mechanism was assumed to be related to imbalanced activation of coagulation and inflammation cascades or the large body size that impacted venous return in obese patients [22]. We did not find the correlation between DVT and male sex and medical comorbidities (e.g., diabetes mellitus). It seemed that these factors for DVT were less influential in trauma patients because the high baseline prevalence of DVT tends to overwhelm other effects. Further research on 
their definitive relationship should be conducted in the future. As an independent risk factor, obesity should be taken into account in predicting the risk of thromboembolic complications when individual risk assessment was conducted for patients following pelvic and acetabular fractures.

In the present study, the incidence of DVT in patients with concurrent injuries was significantly higher than those with isolated pelvic and/or acetabular fractures. The regression model indicated it played an independent role in the formation of a venous clot, although pelvic and acetabular fractures themselves have been generally believed to be at high risk of thromboembolic events. It appeared to be an accumulative effect of polytrauma on amplifying the risk. Our results suggested that patients with accompanied injury demonstrated a remarkably elevated risk of DVT compared to those without other injuries $(\mathrm{OR}=7.85, p<0.001)$, consistent with previously published findings $[8,27]$. This was somewhat contrasting with the findings of a prospective study that the rising risk of DVT in patients with pelvic trauma did not correlate with other non-orthopaedic injuries [4]. This discrepancy might be due to that they did not perform serial venography after admission, to some asymptomatic DVT were unable to detect. We did not find evident relation between high-energy injury and the morbidity of DVT. However, we noticed a delay to surgery was intensely associated with elevated incidence of DVT in patients with pelvic and acetabular fractures. To be specific, a 5.39-fold elevated risk of morbidity was encountered among patients who had an interval between injury to surgery $>9$ days compared with their counterparts. This finding was compatible with previously published studies. For example, Buerger et al. [28] observed a continuously increased prevalence of DVT as immobilization prolonged after acetabular fracture. Wang et al. [25] revealed the incidence of DVT was significantly increased if the surgical intervention was performed more than 2 weeks after pelvic injury. Another study, however, found that diminished morbidity of DVT was observed in patients who received surgery within 2 days of presentation [29]. This inconsistency could be interpreted that the design of the study obscured the nature of the index procedure and the first surgical intervention might not always be fracture fixation. Based on the consideration of DVT prevention, we favored the view that fixation for pelvic and acetabular fractures was recommended at the earliest opportunity for medically ready patients.

Fibrinogen is a relatively abundant plasma protein, which exerts multiple functions, in fibrin clot formation, platelet aggregation, and inflammation as an acute phase reactant. Our ultimate result suggested that patients with FIB $>3.09 \mathrm{~g} / \mathrm{L}$ had a 3.34-fold increased risk of DVT.
This cutoff value of FIB showed an independent association with thromboembolisms after pelvic and acetabular fractures. It is worth noting that after using multivariate logistic regression analysis, the confounding variable PLT was ruled out, which clarified the association between exposure (FBI) and outcome (DVT) in the certain population. Despite the numerous studies regarding FIB associations, the precise relationship between PLT count and FIB levels has yet to be fully investigated.

Hypoalbuminemia is adversely associated with complications and prognosis after major orthopaedic surgeries [30, 31]. A recent study by $\mathrm{Ma}$ et al. [18] found that low albumin level was strongly linked with preoperative DVT in patients undergoing spinal fracture. It was approximately concordant with our findings that patients with a serum albumin less than $32.8 \mathrm{~g} / \mathrm{L}$ and fibrinogen more than 3.09 g/L had 2.71- and 3.34-time elevated risk of DVT following pelvic and acetabular fractures, respectively. Several investigators reported that hypoalbuminemia-induced low oncotic pressure might lead to a hypercoagulable state, which could be reversed by albumin infusion [32]. It also has indicated that the increased fibrinogen levels could be induced by protein loss, which could, in turn, stimulate the synthesis of fibrinogen in the liver [33]. Although the causal relationship between the two parameters was not elucidated in patients with major trauma, they both exhibited independent associations with the presence of DVT before the fixation of pelvic and acetabular fractures. Therefore, we proposed that for patients with hypoalbuminemia and/or hyperfibrinogenemia, the risk of DVT could be reduced by adjusting therapeutic strategies. Combined with or without other tests, the diagnostic value of plasma D-dimer for venous thrombosis was generally acknowledged in trauma patients. However, there was no significant relation between preoperative DVT and plasma D-dimer at admission. We were cautious in the interpretation of this outcome that early D-dimer level exhibited invalidity in predicting subsequent DVT because only the first test result was included, thus leading to the absence of dynamic results.

We conducted a large investigation on the incidence and risk factors of preoperative DVT in patients undergoing pelvic and acetabular fractures. However, the current study has some limitations. Firstly, this is a single-center, retrospective, case-control study, which carries some inherent weaknesses. For example, the risk factors measured in our study represent associated instead of causal relationships, which should be interpreted with clinical practice. And, some variables that potentially influence the statistical results might not be included in this study. Secondly, the main diagnostic method of DVT is color Doppler ultrasonography that may miss the venous 
thrombosis in the pelvis, compromising the effectiveness of the analysis results. Thirdly, to improve the internal validity, patients with certain medical conditions (e.g., injury associated with the fracture that required immediate surgical intervention) were excluded, so our findings may be less applicable to patients with such features.

\section{Conclusion}

In summary, the modern prophylactic regimen reduced the incidence of preoperative DVT in patients with pelvic and acetabular fractures to $13.5 \%$, but orthopaedic surgeons' attention should still be paid to patients with age $>46$ years, BMI $>26.73 \mathrm{~kg} / \mathrm{m}^{2}$, time from injury to surgery $>9$ days, associated injury, ALB $<32.8 \mathrm{~g} / \mathrm{L}$, and FIB $>3.095 \mathrm{~g} / \mathrm{L}$. Better understanding these risk factors can help surgeons refine the risk stratification profile and perform early interdisciplinary management for patients at high risk of DVT.

\begin{abstract}
Abbreviations
DVT: Deep venous thrombosis; ROC curve: Receiver operating characteristic curve; DUS: Duplex ultrasonography; BMI: Body mass index; ASA: American Society of Anesthesiologists; ALB: Albumin; HDL-C: High-density lipoprotein cholesterol; LDL-C: Low-density lipoprotein cholesterol; VLDL: Very-low-density lipoprotein; RBC: Red blood cell count; HGB: Hemoglobin level; PLT: Platelet level, PTprothrombin time; APTT: Activated partial thromboplastin time; FIB: Fibrinogen; OR: Odds ratio; Cl: Confidence interval; SD: Standard deviation.
\end{abstract}

\section{Acknowledgements}

We acknowledge all the patients participating in this study and appreciate the support from Handan Central Hospital on this study.

\section{Author contributions}

WGZ conceived the idea and designed the study. JLZ, TTL, and ZWL collected the relevant data from medical records. WGZ prepared the tables and drafted the manuscript. LL and YZZ performed the statistical analyses. All the authors interpreted the data and contributed to preparation of the manuscript. WGZ and JLZ contributed equally to this manuscript. All authors read and approved the final manuscript.

\section{Funding}

None.

\section{Availability of data and materials}

All the data will be available upon motivated request to the corresponding author of the present paper.

\section{Declarations}

Ethics approval and consent to participate

This study was approved by the ethics committee of the Handan Central Hospital. Informed consent was obtained from all the participants.

\section{Consent for publication}

Written informed consent was obtained from each patient to authorize the publication of their data.

\section{Competing interests}

The authors declare no competing interests.

\section{Author details}

'Department of Orthopaedic Surgery, Handan Central Hospital, Handan 056000, Hebei, People's Republic of China. ${ }^{2}$ Hebei North University,
Zhangjiakou 075000, Hebei, People's Republic of China. ${ }^{3}$ Chengde Medical University, Chengde 067000, Hebei, People's Republic of China. ${ }^{4}$ Department of Orthopaedic Surgery, Third Hospital of Hebei Medical University, Shijiazhuang 050051, Hebei, People's Republic of China.

Received: 24 August 2021 Accepted: 25 January 2022

Published online: 05 February 2022

\section{References}

1. El-Daly I, Reidy J, Culpan P, Bates P. Thromboprophylaxis in patients with pelvic and acetabular fractures: a short review and recommendations. Injury. 2013;44:1710-20. https://doi.org/10.1016/j.injury.2013.04.030.

2. Veerappa LA, Tippannavar A, Goyal T, Purudappa PP. A systematic review of combined pelvic and acetabular injuries. J Clin Orthop Trauma. 2020;11:983-8. https://doi.org/10.1016/j.jcot.2020.09.017.

3. Geerts WH, Code KI, Jay RM, Chen E, Szalai JP. A prospective study of venous thromboembolism after major trauma. New Engl J Med. 1994;331:1601-6. https://doi.org/10.1056/nejm199412153312401.

4. Montgomery KD, Potter HG, Helfet DL. Magnetic resonance venography to evaluate the deep venous system of the pelvis in patients who have an acetabular fracture. J Bone Joint Surg. 1995;77:1639-49. https://doi. org/10.2106/00004623-199511000-00002.

5. Afshari A, et al. European guidelines on perioperative venous thromboembolism prophylaxis: executive summary. Eur J Anaesthesiol. 2018;35(2):77-83. https://doi.org/10.1097/EJA.00000000000000729.

6. Ostrowka C, Bonhomme S, Jouffroy P, Riouallon G. Evaluation of venous thromboembolic complications in patients operated on for pelvic fracture. Orthop Traumatol Surg Res. 2018;104:917-21. https://doi.org/10. 1016/j.otsr.2018.04.017.

7. Kim JW, et al. The incidence and the risk factors of venous thromboembolism in Korean patients with pelvic or acetabular fractures. J Orthop Sci. 2014;19:471-7. https://doi.org/10.1007/s00776-014-0553-z.

8. Wang $\mathrm{P}$, et al. Incidence and risk factors of deep vein thrombosis in patients with pelvic and acetabular fractures. Clin Appl Thrombosis Hemostasis. 2019;25:1076029619845066. https://doi.org/10.1177/10760 29619845066.

9. Sen RK, et al. Risk of postoperative venous thromboembolism in Indian patients sustaining pelvi-acetabular injury. Int Orthop. 2011;35:1057-63. https://doi.org/10.1007/s00264-010-1093-6.

10. Dhillon KS, Askander A, Doraismay S. Postoperative deep-vein thrombosis in Asian patients is not a rarity: a prospective study of 88 patients with no prophylaxis. J Bone Joint Surg. 1996;78:427-30.

11. Wang CJ, et al. Deep vein thrombosis after total knee arthroplasty. J Formosan Med Assoc Taiwan yizhi. 2000;99:848-53.

12. Gupta RK, et al. Results of operative treatment of acetabular fractures from the third world - how local factors affect the outcome. Int Orthop. 2009;33:347-52. https://doi.org/10.1007/s00264-007-0461-3.

13. Liu X, Xu S, Zhang C, Su J, Yu B. Application of a shape-memory alloy internal fixator for treatment of acetabular fractures with a follow-up of two to nine years in China. Int Orthop. 2010;34:1033-40. https://doi.org/ 10.1007/s00264-009-0867-1.

14. Young JW, Burgess AR, Brumback RJ, Poka A. Pelvic fractures: value of plain radiography in early assessment and management. Radiology. 1986;160:445-51. https://doi.org/10.1148/radiology.160.2.3726125.

15. Judet R, Judet J, Letournel E. Fractures of the acetabulum: classification and surgical approaches for open reduction. Preliminary report. J Bone Joint Surg. 1964;46:1615-46.

16. Zhu Y, et al. Epidemiologic characteristics of traumatic fractures in elderly patients during the outbreak of coronavirus disease 2019 in China. Int Orthop. 2020;44:1565-70. https://doi.org/10.1007/s00264-020-04575-0.

17. Gornik HL, Sharma AM. Duplex ultrasound in the diagnosis of lowerextremity deep venous thrombosis. Circulation. 2014;129:917-21. https:// doi.org/10.1161/circulationaha.113.002966.

18. Ma J, et al. Incidence and risk factors predicting deep venous thrombosis of lower extremity following spinal fractures. Sci Rep. 2021;11:2441. https://doi.org/10.1038/s41598-021-82147-x. 
19. Wu L, Cheng B. Analysis of perioperative risk factors for deep vein thrombosis in patients with femoral and pelvic fractures. J Orthop Surg Res. 2020;15:597. https://doi.org/10.1186/s13018-020-02131-5.

20. Ma J, et al. Incidence and risk factors of preoperative deep venous thrombosis in closed tibial shaft fracture: a prospective cohort study. Arch Orthop Trauma Surg. 2020. https://doi.org/10.1007/s00402-020-03685-z.

21. Park SJ, et al. Incidence and factors predicting venous thromboembolism after surgical treatment of fractures below the hip. J Orthop Trauma. 2015;29:e349-354. https://doi.org/10.1097/bot.0000000000000336.

22. Cushman M. Epidemiology and risk factors for venous thrombosis. Semin Hematol. 2007;44:62-9. https://doi.org/10.1053/j.seminhematol.2007.02. 004.

23. McCarthy R, Leslie T, Williams DJ. Obesity in general elective surgery. Lancet (London, England). 2003;362:577. https://doi.org/10.1016/s01406736(03)14128-1.

24. Obalum DC, et al. A review of obesity and orthopaedic surgery: the critical issues. Niger Postgrad Med J. 2012;19:175-80.

25. Morris $\mathrm{BJ}$, et al. Obesity increases early complications after high-energy pelvic and acetabular fractures. Orthopedics. 2015;38:e881-887. https:// doi.org/10.3928/01477447-20151002-54

26. Karunakar MA, Shah SN, Jerabek S. Body mass index as a predictor of complications after operative treatment of acetabular fractures. J Bone Joint Surg. 2005;87:1498-502. https://doi.org/10.2106/jbjs.D.02258.

27. Fishmann AJ, Greeno RA, Brooks LR, Matta JM. Prevention of deep vein thrombosis and pulmonary embolism in acetabular and pelvic fracture surgery. Clin Orthop Relat Res. 1994;305:133-7.

28. Buerger PM, Peoples JB, Lemmon GW, McCarthy MC. Risk of pulmonary emboli in patients with pelvic fractures. Am Surg. 1993;59:505-8.

29. Arroyo W, Nelson KJ, Belmont PJ Jr, Bader JO, Schoenfeld AJ. Pelvic trauma: what are the predictors of mortality and cardiac, venous thrombo-embolic and infectious complications following injury? Injury. 2013;44:1745-9. https://doi.org/10.1016/j.injury.2013.08.007.

30. Bohl DD, Shen MR, Kayupov E, Cvetanovich GL, Della Valle CJ. Is hypoalbuminemia associated with septic failure and acute infection after revision total joint arthroplasty? A study of 4517 patients from the National Surgical Quality Improvement Program. J Arthroplasty. 2016;31:963-7. https://doi.org/10.1016/j.arth.2015.11.025.

31. Aldebeyan S, Nooh A, Aoude A, Weber MH, Harvey EJ. Hypoalbuminaemia-a marker of malnutrition and predictor of postoperative complications and mortality after hip fractures. Injury. 2017;48:436-40. https://doi. org/10.1016/j.injury.2016.12.016.

32. Kim SB, Yang WS, Lee SK, Chi HS, Park JS. Effect of increasing serum albumin on haemostatic factors synthesized in the liver in CAPD patients. Nephrol Dial Transplant. 1998;13:2053-8. https://doi.org/10.1093/ndt/ 13.8.2053.

33. Bartens W, Nauck M, Schollmeyer P, Wanner C. Elevated lipoprotein(a) and fibrinogen levels [corrected] increase the cardiovascular risk in continuous ambulatory peritoneal dialysis patients. Peritoneal Dial Int J Int Soc Peritoneal Dial. 1996;16:27-33.

\section{Publisher's Note}

Springer Nature remains neutral with regard to jurisdictional claims in published maps and institutional affiliations.

Ready to submit your research? Choose BMC and benefit from:

- fast, convenient online submission

- thorough peer review by experienced researchers in your field

- rapid publication on acceptance

- support for research data, including large and complex data types

- gold Open Access which fosters wider collaboration and increased citations

- maximum visibility for your research: over $100 \mathrm{M}$ website views per year

At BMC, research is always in progress.

Learn more biomedcentral.com/submissions 